\title{
Performance Comparison of Thin-film Composite Forward Osmosis Membranes
}

\author{
Winny Fam¹, Sherub Phuntsho ${ }^{1}$, Jong Hwa Lee ${ }^{2}$ and Ho Kyong Shon ${ }^{1, *}$ \\ ${ }^{1}$ School of Civil and Environmental Engineering, University of Technology, Sydney (UTS), Post \\ Box 129, Broadway, NSW 2007, Australia. \\ ${ }^{2}$ R\&D Institute/Filter R\&D Team 2, WoongJin Chemical Co., Ltd. KANC 906-10, Iui-dong, \\ Yeongtong-gu, Suwon-si, South Korea \\ *Corresponding author: Email: Hokyong.Shon-1 @uts.edu.au
}

\begin{abstract}
Forward osmosis (FO) is an emerging low-energy technology. Much effort was given on developing a new membrane material and engineering membrane structure to improve the performance of FO membranes. The performances of two newly developed polyamide based thin film composite (TFC) FO membranes were tested and compared with the commercially available cellulose triacetate (CTA) FO membrane. The intrinsic properties of the two TFC FO membranes determined in RO experiments indicate superior performance of the membranes. When tested in FO experiments, TFC membranes delivered consistent results, confirming their outstanding permeability and selectivity properties. The study shows that future studies on membrane fouling will be necessary to have a better understanding of membrane performance and to further optimize membrane properties.
\end{abstract}

\section{Introduction}

Forward osmosis (FO) process, driven only by the osmotic gradient between two solutions of different osmotic concentrations, is a promising low energy desalination technology. In addition, FO holds high potentials in other applications, including emergency drinks from brackish or sea water [1], power generation[2], landfill leachate treatment[3], liquid foods treatment [4], and irrigation [5-7]. Although the concept of the process is well documented, one of major drawbacks of the process that still presents a challenge is concentration polarization $(\mathrm{CP})$ phenomenon. Internal $\mathrm{CP}$ or ICP is a unique 
process in FO process and is mainly responsible for resulting in lower water flux than the expected flux based on the bulk osmotic concentration gradient between the draw solution (DS) and the feed solution (FS) [8, 9]. Internal CP (ICP) is particularly challenging because it occurs within the membrane support layer and cannot be simply mitigated by hydrodynamic operating conditions as for external CP (ECP) [10].

A lot of effort was put on improving the FO performance by modifying the structural properties of the membrane, particularly the support layer to reduce the ICP effects. Cellulose triacetate (CTA) asymmetric membrane was the first tailored membrane commercialized for FO applications by Hydration Technology Innovations Inc (Albany, OR, USA). Although this CTA membrane has been widely used for many FO application studies, its water flux remains lower than the pressure-driven membranes at the same bulk osmotic pressure gradient and moreover, it has a limited range to $\mathrm{pH}$ tolerability $(\mathrm{pH}$ 4.0 - 8.0). CP effects remain a significant challenge that limits the FO process efficiency, and thus more innovative breakthrough is required to solve the $\mathrm{CP}$ issues, to improve the process efficiency and make the process more competitive to the existing desalination technology.

Most research currently focus on synthesizing reliable thin film composite (TFC) membranes comprising polyamide (PA) active layer on top of thick microporous polysulfone support layer[11-14]. TFC membranes are promising candidates because they historically have better membrane performance in RO applications. Recently, two different proprietary polyamide (PA) TFC membranes were synthesized by two independent membrane companies for FO applications. The objective of the study is to evaluate the performances of the membranes and to compare them with that of commonly studied commercial TCA FO membrane. The performance of each membrane has been measured in terms of water flux and rejection in RO mode and in terms of water flux and reverse solute flux in FO mode of operation.

\section{Materials and Methods}




\subsection{Membranes and draw solutions}

Two different types of proprietary flat sheet TFC FO membranes designated as TFC-1 and TFC-2 were used and compared with the commercially available cellulose triacetate (CTA) FO membrane supplied by Hydration Technologies Innovation, (HTI, Albany, OR, USA). TFC-2 membrane was supplied by Woongjin Chemicals (Korea) while the source for TFC-1 is withheld for commercial interest at behest of the supplier. Both the membranes were polyamide-based thin film composite membranes as disclosed by the supplier. The detail chemistry of the TFC membrane has not been performed and therefore not included within the scope of this study. Few basic data as provided by the supplier are enlisted in Table 1. The properties of the CTA membrane have been reported in many other studies [15-17].

Despite the limited tolerance to chlorine attack, PA based TFC membranes are known to offer more advantages in terms of membrane performance and durability, such as wider operating $\mathrm{pH}$ and temperature ranges [11]. The data also shows that the contact angles of PA TFC membranes are smaller, indicating higher degree of hydrophilicity. Hence, water should be able to permeate more easily, and higher water flux will be expected from those membranes. The overall physical thickness of the two virgin membranes measured using digital micrometer (Model 293-330 Mitutoyo, Japan) indicates that TFC-2 membrane is the thickest $(142 \pm 2 \mu \mathrm{m})$ than the TFC- 1 and CTA FO membranes.

The SEM micrographs of TFC-2 membrane are shown in Figure 1. The top view of the active layer appears continuous with a ridge-and-valley morphology, indicating potential of good selectivity property. Cross-sectional SEM micrographs show that the polysulfone support layer spans along the membrane with finger-like morphology. Near the top of the support layer, the morphology appears denser, which is critical for the formation of thin active layer. No change in membrane morphology was observed after the membrane was compacted after the experiments. 
Table 1: Physical and chemical properties of membranes as provided by the manufacturer for TFC FO membranes and from various literature for CTA membrane.

\begin{tabular}{lccccccc}
\hline Sample & $\begin{array}{c}\text { Active } \\
\text { layer }\end{array}$ & \multicolumn{2}{c}{$\begin{array}{c}\text { Contact angle }\left(^{\circ}\right) \\
\text { material }\end{array}$} & $\begin{array}{c}\text { Zeta potential at } \\
\mathrm{pH} \mathrm{6}(\mathrm{mV})\end{array}$ & $\begin{array}{c}\text { Operating } \\
\mathrm{pH}\end{array}$ & $\begin{array}{c}\text { Membrane } \\
\text { thickness }\end{array}$ & Ref \\
\cline { 3 - 6 } & & $\begin{array}{c}\text { active } \\
\text { layer }\end{array}$ & $\begin{array}{c}\text { support } \\
\text { layer }\end{array}$ & active layer & & $(\mathrm{mm})$ & \\
\hline CTA & cellulose & 76.6 & 81.8 & -2.1 & $3-8$ & $93 \pm 3$ & {$[18]$} \\
& triacetate & & & & & & \\
TFC-1 & polyamide & 45 & 45 & 86 & $2-12$ & $116 \pm 1$ \\
TFC-2 & polyamide & 15 & 15 & 69 & $2-12$ & $148 \pm 6$ & \\
\hline
\end{tabular}

Draw solution (DS) was prepared by dissolving different concentrations of potassium chloride (KCl, Chem Supply, Australia) in deionized (DI) water. The feed solution (FS) used consisted of either deionized (DI) water or sodium chloride ( $\mathrm{NaCl}$, Sigma Aldrich, Australia) solution prepared in DI Water. $\mathrm{KCl}$ was chosen due to its well-established thermodynamic properties $[19,20]$, high osmotic pressure and excellent performance as draw solution for forward osmosis fertigation application $[5,6] . \mathrm{NaCl}$ solution $(5000$ $\mathrm{mg} / \mathrm{L}$ ) has been used as model brackish water FS since the majority of solutes present in the brackish water consists of $\mathrm{Na}^{+}$and $\mathrm{Cl}^{-}$ions.

\subsection{Measurement of membrane intrinsic separation properties in Reverse osmosis mode}

The pure water permeability coefficient $A$, salt rejection, and the solute permeability coefficient $B$ were evaluated using laboratory-scale crossflow reverse osmosis (RO) unit with the active layers of the membrane facing the feed. A laboratory-scale RO cell with channel dimensions of both channels were $7.7 \mathrm{~cm}$ in length, $2.6 \mathrm{~cm}$ in width, and $0.3 \mathrm{~cm}$ in depth, providing an effective membrane area of $20.02 \mathrm{~cm}^{2}$ was used for experiments in RO mode to test the pure water permeability and the salt rejection properties of the membranes. The feed solution was supplied at a volumetric flow rate of $400 \mathrm{ml} / \mathrm{min}$. Temperature of the feed solution was maintained at $25 \pm 1^{\circ} \mathrm{C}$ using a water bath controlled 
by heater/chiller. To measure water flux, the experiment was timed and the volume of permeate collected was measured. The pure water flux was measured for each transmembrane pressure (2-10 bar) at a constant temperature of $25 \pm 1^{\circ} \mathrm{C}$. The flux measurements was then plotted against the applied pressure and fitted by least-squares linear regression to obtain the permeability coefficient.

For salt rejection, brackish water $(5000 \mathrm{mg} / \mathrm{L} \mathrm{NaCl}$ solution) was used with the applied pressure at 10 bar. The concentrations of $\mathrm{NaCl}$ in the feed $C_{f}$ and permeate $C_{p}$ were determined by conductivity measurement. Salt rejection $R$ was calculated according to the equation:

$$
R=\left(1-\frac{C_{p}}{C_{f}}\right) \times 100 \%
$$

The solute $(\mathrm{NaCl})$ permeability $B$ of each membrane was determined by a linear fitting of water permeability and salt rejection under different applied pressures according to the equation [21]:

$$
\frac{1-R}{R}=\frac{1}{(\Delta P-\Delta \pi) A} B
$$

where $\Delta \pi$ is the osmotic pressure difference between the feed and permeate.

\subsection{Forward osmosis experimental setup and FO performance evaluation}

A laboratory-scale FO cell with dimensions similar to that of RO cell but with channel on both sides of the membrane was used for all FO experiments. The feed and draw solutions were supplied at volumetric crossflow rates of $400 \mathrm{ml} / \mathrm{min}$ using two variable speed peristaltic pumps (Cole-Palmer, Illinois) in co-current mode to minimize strain on the suspended FO membranes [22]. The temperature of the feed and draw solutions was maintained at $25 \pm 1^{\circ} \mathrm{C}$ using a water bath controlled by heater/chiller. 
Each experiment was carried out for minimum $4 \mathrm{~h}$ duration with initial volumes of the feed and draw solutions were 2 liters. Experimental runs were carried out in batch mode in which case the DS and FS were continuously recycled back to their respective tanks. The performance of the membrane was evaluated in terms of water flux, reverse solute flux (RSF), and specific reverse solute flux (SRSF). Water permeate flux $J_{w}$ was directly measured by connecting DS to a digital mass scale interfaced with a computer. When DI Water was used as FS, RSF was determined by using a multimeter (CP-500L, ISTEK) to measure the electrical conductivity (EC) of the feed solution at the end of the each experiment.

RSF was determined using DI water as the feed according to the following formula:

$$
J w=\frac{C_{F}(2-\Delta V)}{A_{m} t}
$$

where $J_{s}$ is the reverse solute flux through the FO membrane, $A_{m}$ is the effective membrane surface area, $C_{F}$ is the final feed solute concentration at the end of the experiment and $\Delta V$ is the volume of the water that has passed through the membrane from feed to DS over an operating period of $t$.

SRSF was then calculated as the ratio of the reverse solute flux to the water flux $\mathbf{J}_{\mathrm{w}}$ by:

$$
S R S F=\frac{J_{S}}{J_{w}}
$$

\section{Results and Discussions}

\subsection{Intrinsic properties of the membrane tested in RO mode}

The $A, R$, and $B$ values of FO membranes were determined in the crossflow RO operation as described in earlier section. It is well-known for any polymer, membranes with high water permeability can be obtained by sacrificing the salt rejection, or vice versa. Table 2 shows that both TFC membranes have higher water permeability and better $\mathrm{NaCl}$ 
rejection than CTA membrane indicating that polyamide is a more superior material for membrane separation performance. TFC-2 in particular exhibits the highest water permeability, approximately 25 times higher than that of CTA membrane, and decent salt rejection. Although, a significant increase in salt rejection can be obtained at higher operating pressures [23] however, we avoided high operating pressure in order to prevent the membrane from being damaged as the membrane appears more fragile when handling in comparison to CTA FO membrane.

The ratio $\mathrm{B} / \mathrm{A}$ was also calculated to compare the selectivity of different membranes. It is highly desirable to obtain low $\mathrm{B} / \mathrm{A}$ ratio (i.e. high selectivity) to minimize solute reverse diffusion from DS [24] during the FO process, decrease the membrane susceptibility to fouling [25], and improve the contaminant rejection [26] . TFC-2 was observed to exhibit the lowest $\mathrm{B} / \mathrm{A}$ ratio, followed by TFC-1 and CTA, indicating improved selectivity and more superior separation properties of the TFC membranes.

Table 2: Intrinsic properties of the three FO membranes. Pure water permeability was determined using DI water as feed in RO mode at applied pressures ranging from 2 to 10 bars at 2 bar interval. Salt rejection was tested using simulated brackish water $(5,000 \mathrm{mg} / \mathrm{l}$ $\mathrm{NaCl})$ at applied pressure at 10 bar.

\begin{tabular}{cccccc}
\hline Sample & Pure water permeability A & NaCl Rejection & Salt permeability B & B/A \\
\cline { 2 - 3 } & $1 \mathrm{~m}^{-1} \mathrm{~h}^{-1} \mathrm{bar}^{-1}$ & $10^{-12} \mathrm{~m} / \mathrm{s} \mathrm{Pa}$ & & & \\
& & & $\mathrm{R}(\%)$ & $\left(10^{-7} \mathrm{~m} / \mathrm{s}\right)$ & $\left(10^{2} \mathrm{kPa}\right)$ \\
\hline CTA & $0.64 \pm 0.03$ & 1.8 & $60 \pm 4$ & 9.8 & 3.7 \\
TFC-1 & $2.4 \pm 0.08$ & 6.9 & $86 \pm 5$ & 6.5 & 1.4 \\
TFC-2 & $15 \pm 1.12$ & 43 & $69 \pm 5$ & 29 & 0.7 \\
\hline
\end{tabular}

\subsection{Performance of TFC membranes in the FO process}

Figure 2 shows the performances of the three membranes in terms of water fluxes in FO mode of operation (support layer facing DS) at various DS concentrations with DI water as feed (Figure 2a) and simulated brackish water $(5,000 \mathrm{mg} / \mathrm{l}$ of $\mathrm{NaCl})$ as feed (Figure $2 \mathrm{~b})$ 
while Figure 3 shows the permeate water flux in PRO mode of operation (active layer facing the DS) As expected, operating the FO process at higher DS concentration resulted in higher water permeate flux because of the higher net osmotic gradient that drives the water flux across the membrane. This was true for all cases both in Figures 2 and 3. With DI water as feed, TFC-2 exhibits the highest permeate water flux, followed by TFC-1 and CTA membranes (Figure 2a). The same trend is also observed when brackish water is used as feed as shown in Figure 2b, and consistent with the RO experiment result for the water permeability coefficients. TFC membranes have characteristically higher water flux due to their fabrication procedure that enables property optimization of membrane support layer and rejecting layer. It is important to notice that permeate flux through TFC membranes is slightly higher at low DS concentration, and it seems to level off at a higher DS concentration. This is most likely due to more ICP effects that occurs within the support layers of the TFC membranes [27]. The effect of CP on CTA FO membrane, however, is less pronounced on CTA FO membrane as shown by linear increase of water flux throughout the DS concentration.

Figure 3 shows the comparative performances of the three membranes in PRO mode of operation (active layer facing the DS and the support layer facing the feed water) with DI water as feed (Figure 3a) and brackish water as feed water (Figure 3b). Comparing Figure 2 and Figure 3, it is clear that the water permeate flux in PRO mode of operation is considerably higher than the FO mode of operation. Similar order of permeate flux noticed in FO mode is again observed in PRO mode: TFC-2 > TFC-1 > CTA. At high DS concentration $(3 \mathrm{M} \mathrm{KCl})$, the permeate flux performance of TFC membranes decreases due to contribution of the concentrative ICP within the membrane support layer in addition to the dilutive ECP already present on the active layer side of the membrane facing the DS. This signifies the role of ICP (whether dilutive or concentrative). The nonlinearity in the water flux with the DS concentration is also an indication that the ICP and ECP effects are more pronounced when higher DS concentration used for FO process.

TFC-2 not only exhibited the highest water flux but also showed the lowest SRSF as shown in Figure 4 despite having descent salt rejection data in the RO mode (Table 2). 
The performance of TFC-1 membrane either in FO or RO process is behind TFC-2, but is consistently better than that of CTA. The superior properties of TFC-2 are mainly attributed to highly hydrophilic active layer which allows water to permeate easily. All results agree with the prediction based on a model developed using independently determined membrane transport coefficients, stating that SRSF is related to the ratio of B/A by the relationship[28]:

$$
\frac{J_{w}}{J_{s}} \approx \frac{A}{B} n R_{g} T
$$

where $n$ is the number of dissolved species created by draw solute, $R_{g}$ the ideal gas constant, and $T$ the absolute temperature. It is however worthwhile to note that if the experimental SRSF values were to be compared with B/A ratio in Table 2, the solute permeability constants $\mathrm{B}$ would have to be determined using $\mathrm{KCl}$ solution as feed in $\mathrm{RO}$ experiments whereas the reported values in this study were of $\mathrm{NaCl}$.

These results indicate that, the performance of the two PA-based TFC membranes evaluated in this study need further reengineering and optimization in their support structure since the ICP was observed to play a significantly limiting role in decreasing the water flux when tested in FO and PRO mode of operation. The high salt rejection properties of TFC-1 membrane in RO mode did not translate into lower SRSF in FO process also showing other unknown phenomenon taking place within the support structure of the current TFC membranes. 


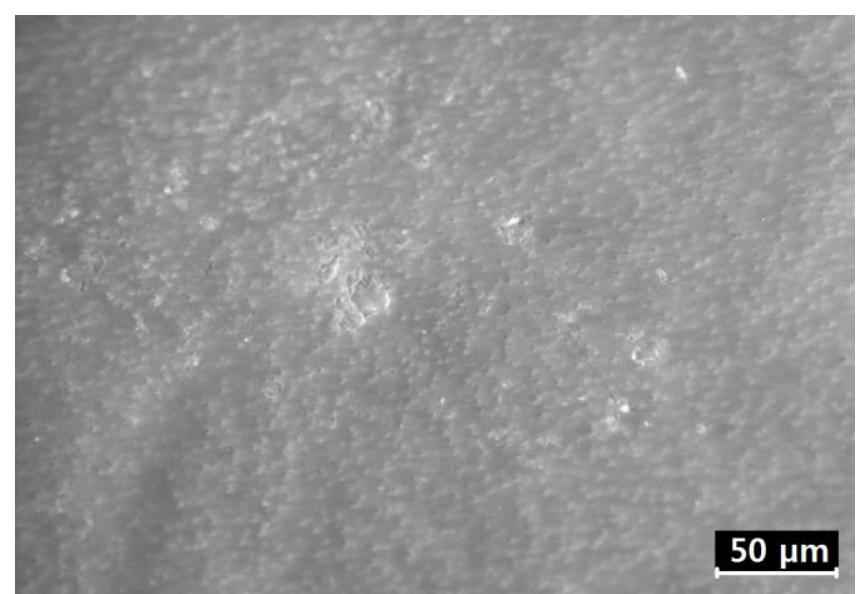

(a)

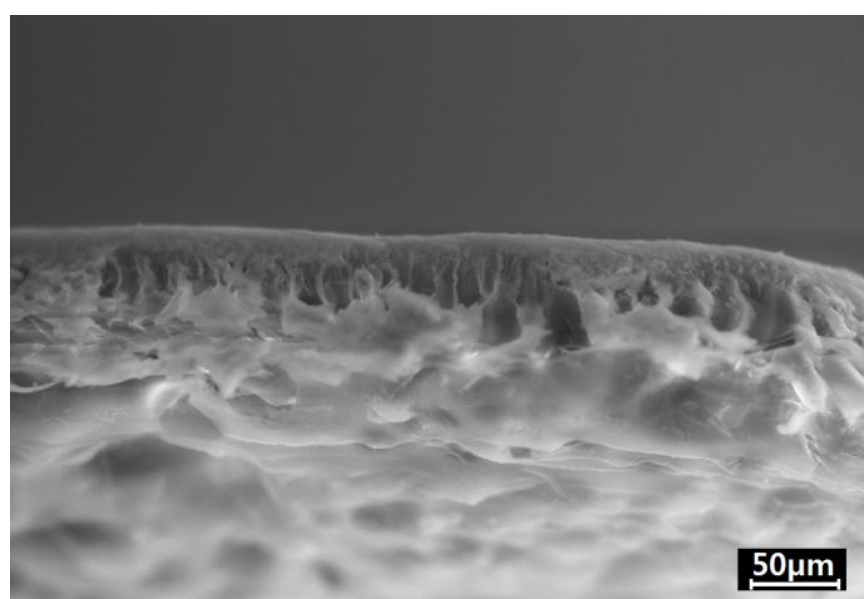

(b)

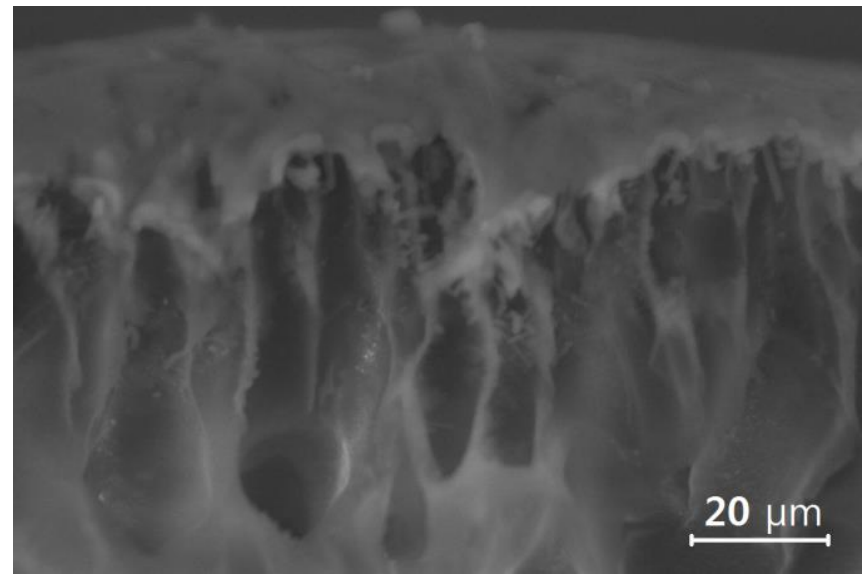

(c)

Figure 1. SEM micrographs of TFC-2 displaying (a) the top surface of the polyamide active layer, (b) membrane cross section, and (c) a magnified view of the sponge-like support layer near the active layer. 


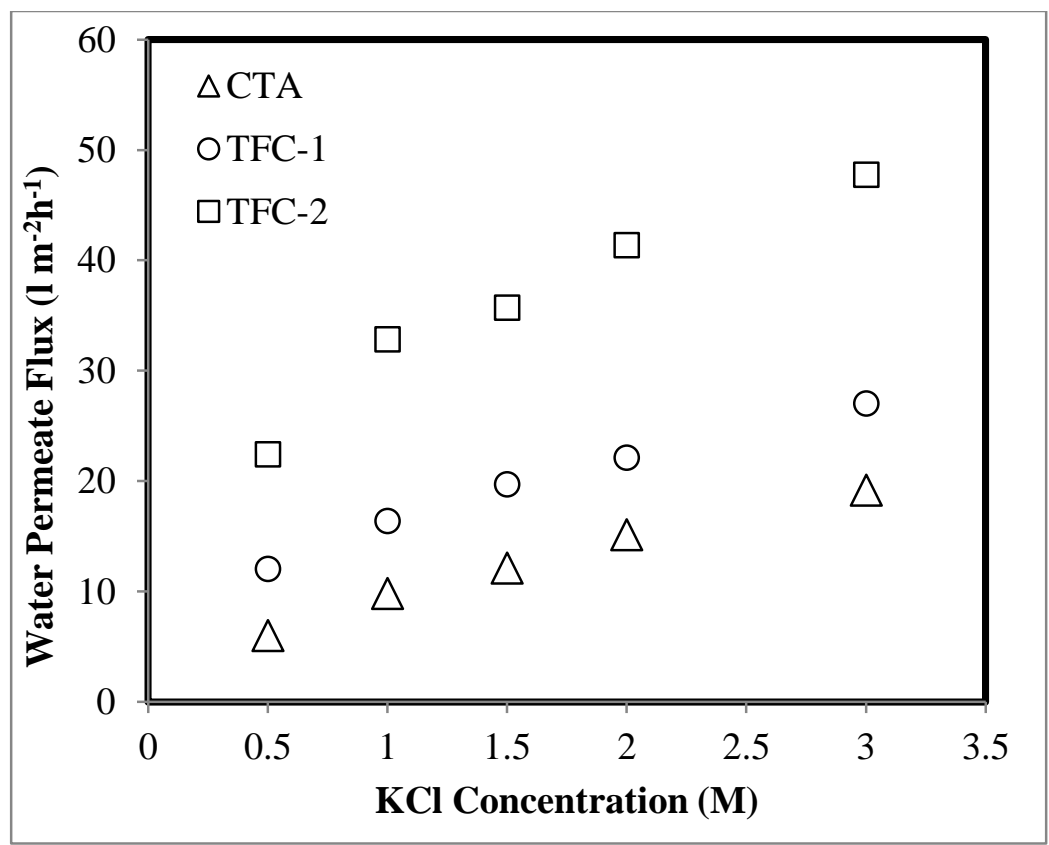

(a)

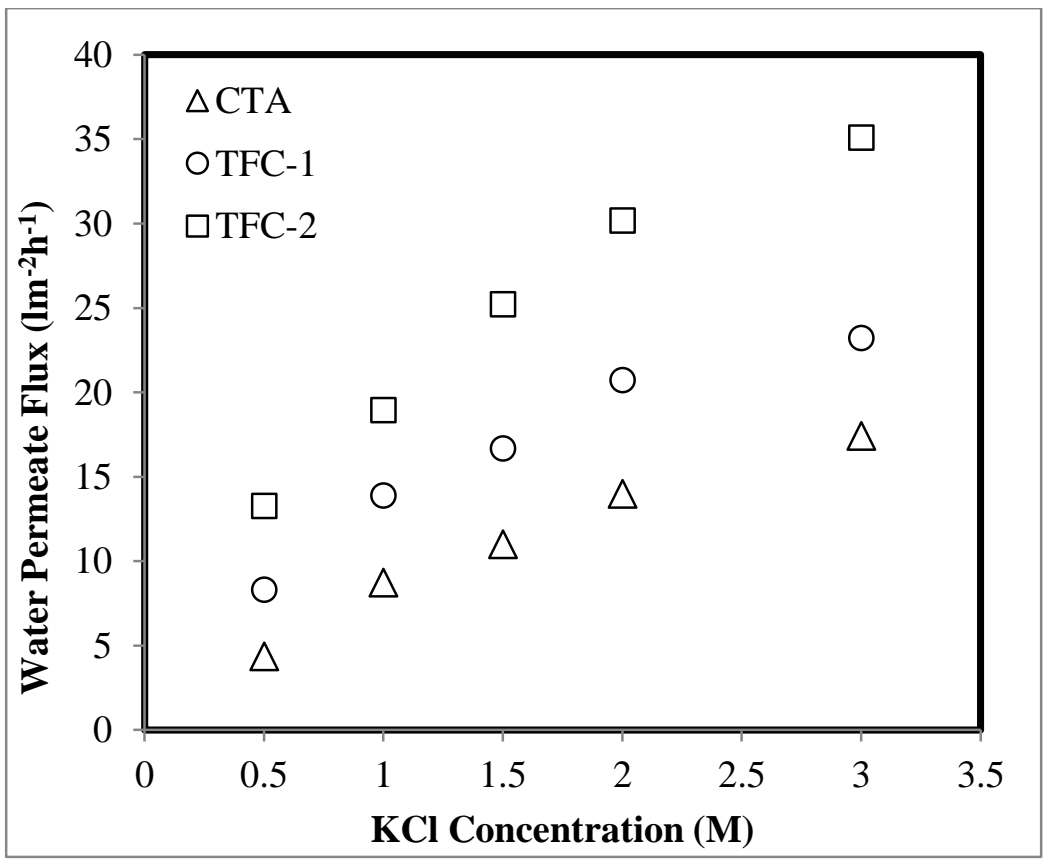

(b)

Figure 2. Comparison of water permeate flux with (a) DI water as feed and (b) brackish water $(5000 \mathrm{mg} / \mathrm{l} \mathrm{NaCl})$ as feed for the three membranes. Experiments were carried out with $\mathrm{KCl}$ solution as $\mathrm{DS}$ with concentration ranging from $0.5-3 \mathrm{M}$ at temperature of $25 \pm 1{ }^{\circ} \mathrm{C}$ and volumetric crossflow rates of $400 \mathrm{ml} / \mathrm{min}$ with membrane active layers facing DS (FO mode). 


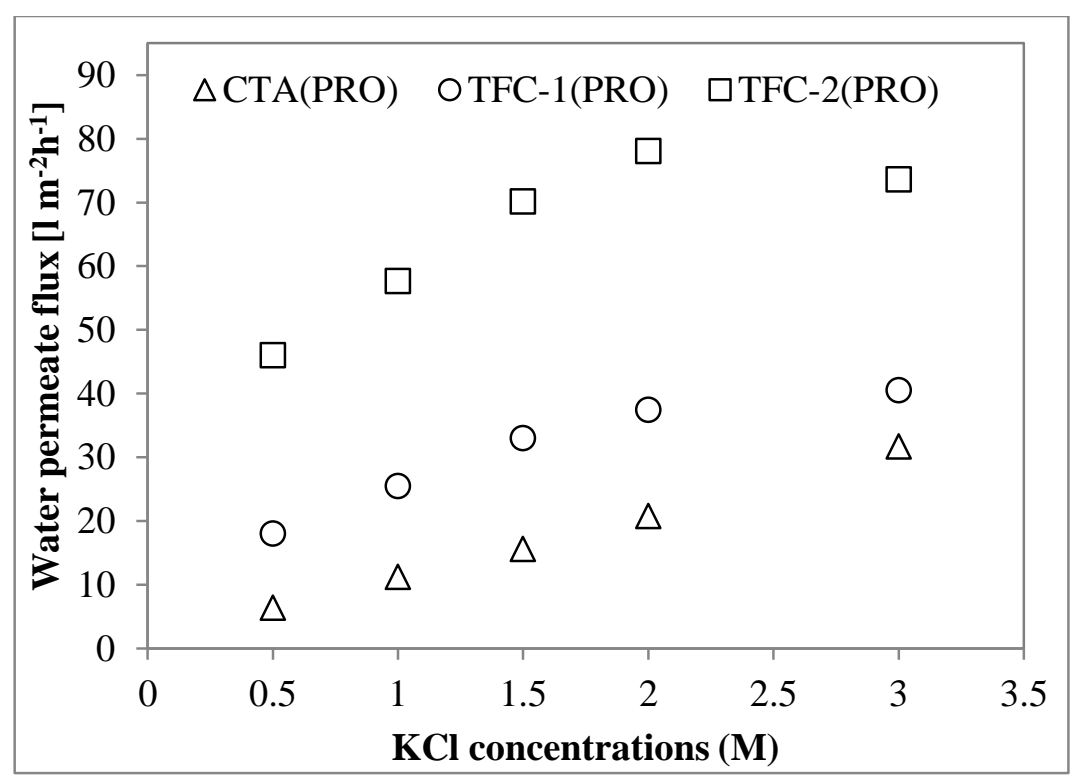

(a)

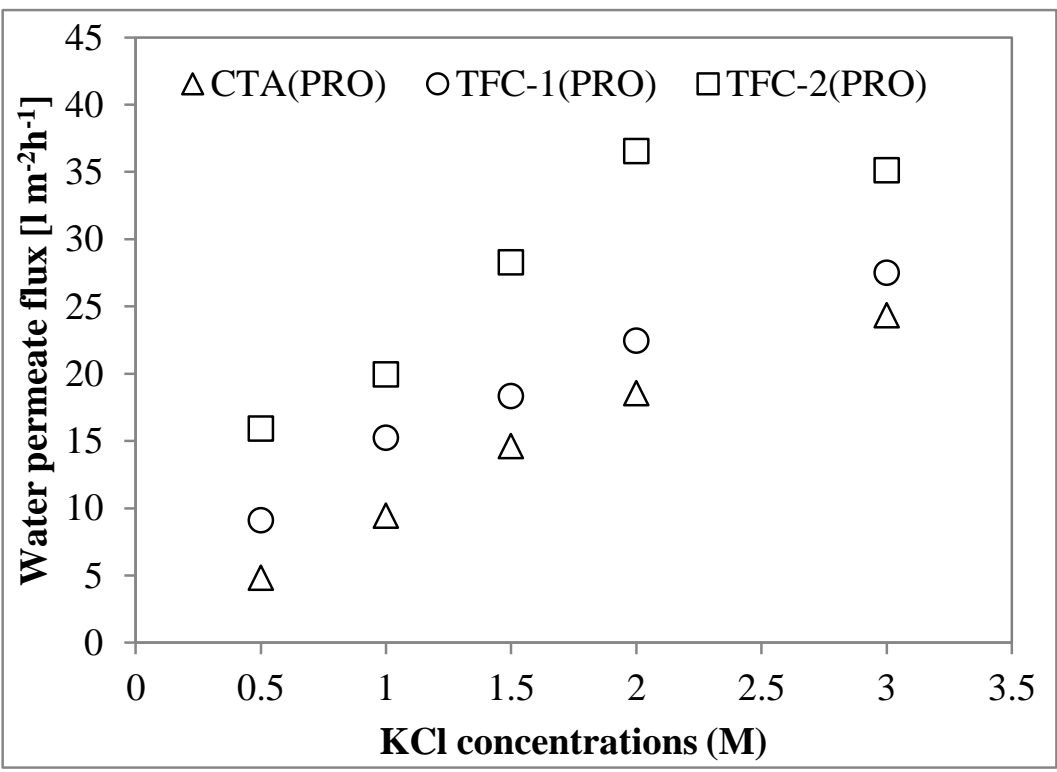

(b)

Figure 3. Permeate water fluxes of the three membranes in PRO mode of operation. 


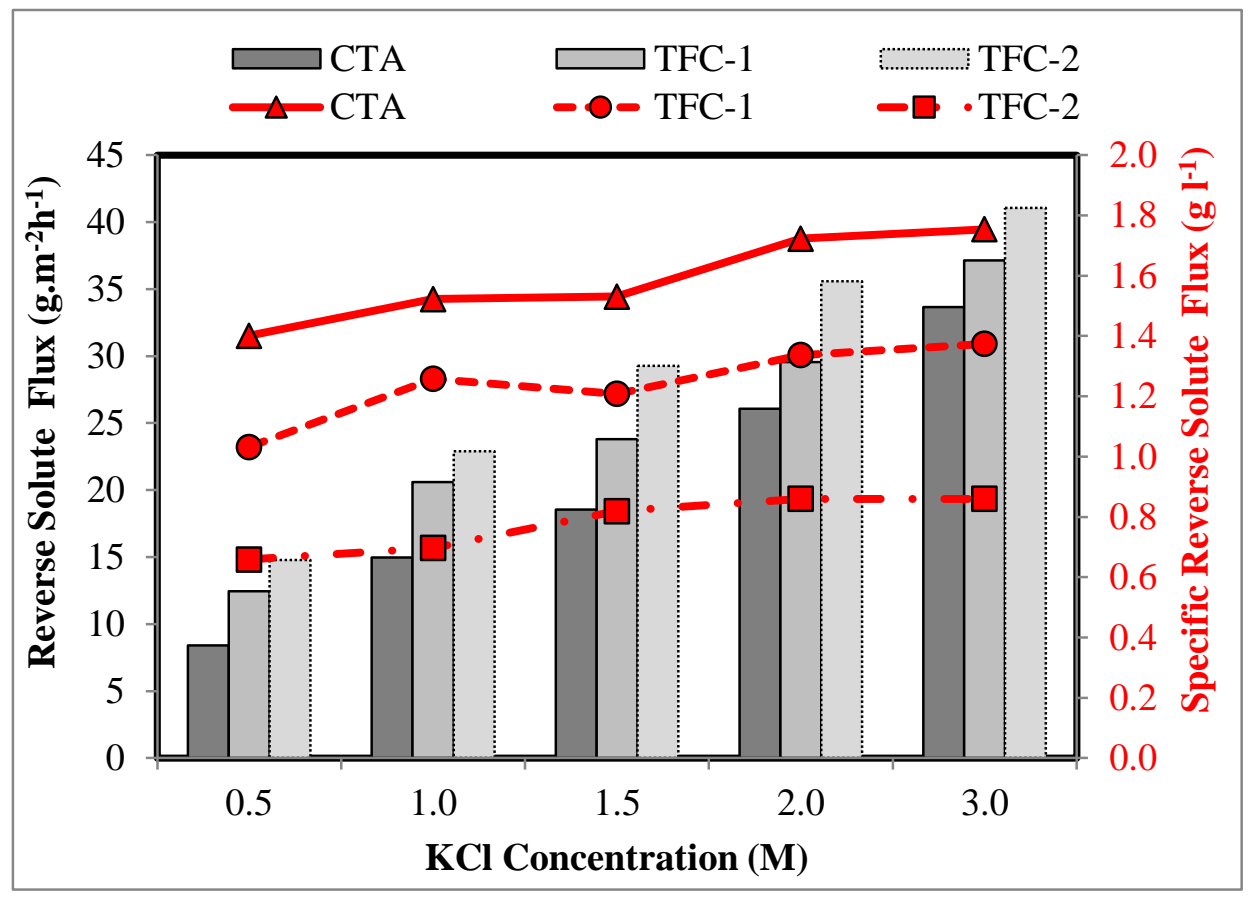

Figure 4. Performance of the three FO membranes in terms of specific reverse solute flux with $\mathrm{KCl}$ as DS and DI water as FS

\section{Conclusions}

Membrane performances for three FO membranes (CTA, TFC-1, and TFC-2) were investigated and compared in RO and FO operations. The membrane intrinsic properties obtained from RO experiments demonstrated that TFC membranes are more superior due to their excellent active layer water permeability and salt rejection properties. Their superior properties are confirmed when tested for FO process both in FO mode and PRO mode of operation at lab-scale level. TFC-2 is of a particular interest in the study, and the effect of membrane orientation was further investigated to obtain more insights on permeability-selectivity trade-off as well as the effect of ICP. When the active layer faced the feed solution (FO mode), water flux generated was less than the case where the active layer faced the draw solution (PRO mode). However, the reverse solute permeation observed in FO mode was also lower, demonstrating the coupling between solute and solvent permeation and/or greater ICP effects. Further investigations such as fouling 
studies, particularly on TFC membranes, would be necessary to have a better understanding of membrane properties and characteristics to tailor and fabricate membranes for certain applications.

\section{Acknowledgements}

This study was supported by Woonjin Chemical Co. Ltd.

\section{Nomenclature}

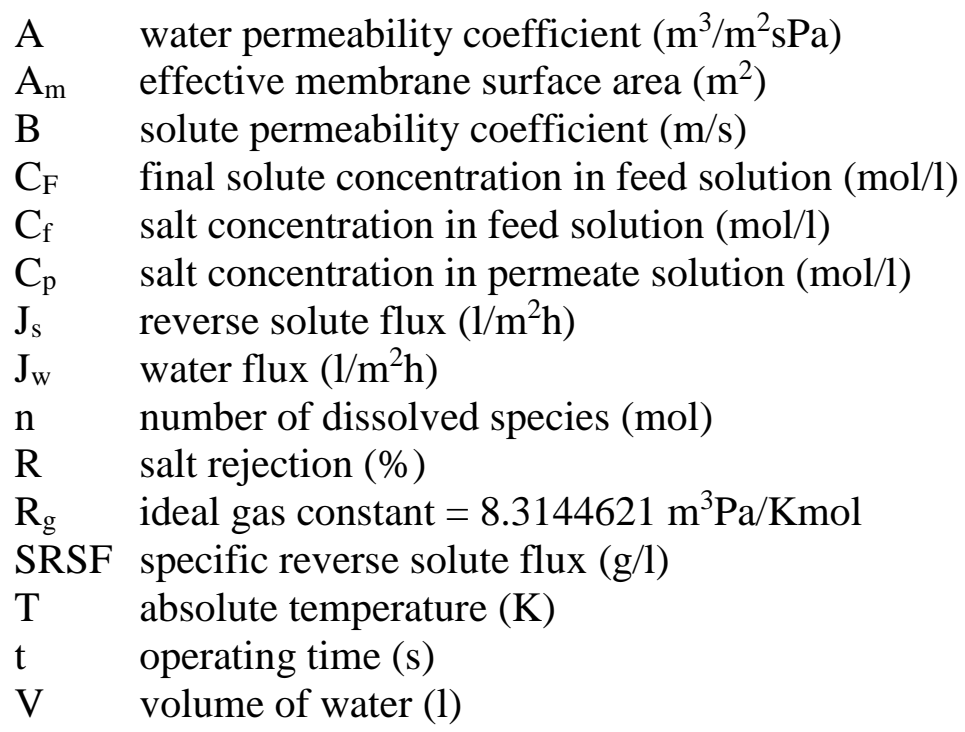

Greek letters

$\Delta \quad$ difference operator

$\pi \quad$ osmotic pressure (bar)

\section{References}

1. Cohen, D., Mixing moves osmosis technology forward, in Chemical Processing magazine October 2004.

2. Aaberg, R.J., Osmotic power - a new and powerful renewable energy source in ReFocus2003. p. 48-50.

3. Beaudry, E.G. and J.R. Herron. Direct osmosis for concentrating wastewater in Proceedings of the 27th International Conference on Environmental Systems. 1997. Lake Tahoe, NV. 14 - 17 July 1997.

4. $\quad$ Popper, K., et al., Dialyzer concentrates beverages Food Engineering, 1966. 38: p. 102-104. 
5. Phuntsho, S., et al., A novel low energy fertilizer driven forward osmosis desalination for direct fertigation: evaluating the performance of fertlizer draw solutions. Journal of Membrane Science, 2011. 375: p. 172-181.

6. Phuntsho, S., et al., Fertiliser drawn forward osmosis desalination: the concept, performance and limitations for fertigation. Reviews in Environmental Science and Technology, 2012. 11(2): p. 147-168.

7. $\quad$ Phuntsho, S.S., H.K.; Majeed, T.; El Salibya, I.; Vigneswarana, S.; Kandasamy, J.; Hong, S.; and Leeb, S. , Blended fertilisers as draw solutions for fertiliser drawn forward osmosis desalination. Environmental Science \& Technology 2012. 46(8): p. 4567-4575.

8. McCutcheon, J.R. and M. Elimelech, Influence of concentrative and dilutive internal concentration polarization on flux behavior in forward osmosis. Journal of Membrane Science, 2006. 284: p. 237-247.

9. Loeb, S., et al., Effect of porous support fabric on osmosis through a LoebSourirajan type asymmetric membrane. Journal of Membrane Science, 1997. 129(129): p. 243-249.

10. Wang, Y., et al., Direct microscopic observation of forward osmosis membrane fouling. Environmental Science \& Technology, 2010. 44: p. 7102-7109.

11. Wei, J., et al., Synthesis and characterization of flat-sheet thin film composite forward osmosis membranes. Journal of Membrane Science, 2011. 372(1-2): p. 292-302.

12. Tip, N.Y., et al., High performance thin-film composite forward osmosis membrane. Environmental Science \& Technology, 2010. 44: p. 3812-3818.

13. Tiraferri, A., et al., Relating performance of thin-film composite forward osmosis membranes to support layer formation and structure. Journal of Membrane Science, 2011. 367: p. 340-352.

14. Setiawan, L., et al., Fabrication of novel poly(amide-imide) forward osmosis hollow fiber membranes with a positively charged nanofiltration-like selective layer. Journal of Membrane Science, 2011. 369: p. 196-205.

15. Cath, T.Y., A.E. Childress, and M. Elimelech, Forward osmosis: Principles, applications, and recent developments: Review. Journal of Membrane Science, 2006. 281(2006): p. 70-87.

16. McCutcheon, J.R., R.L. McGinnis, and M. Elimelech, Desalination by ammoniacarbon dioxide forward osmosis: Influence of draw and feed solution concentrations on process performance. Journal of Membrane Science, 2006. 278(2006): p. 114-123.

17. Tang, C.Y., et al., Coupled effects of internal concentration polarization and fouling on flux behavior of forward osmosis membranes during humic acid filtration. Journal of Membrane Science, 2010. 354(1-2): p. 123-133.

18. X. Jin, Q.S., X. Ang, C.Y. Tang, Removal of boron and arsenic by forward osmosis membrane: Influence of membrane orientation and organic fouling. $\mathrm{J}$. Membr. Sci., 2012. 389: p. 182-187.

19. H.S. Harned, M.A.C., The thermodynamics of aqueous potassium chloride solutions from electromtive force measurements. J. Am. Chem. Soc., 1937. 59(7): p. 1290-1292. 
20. J.I. Partanen, A.K.C., Re-evaluation of the thermodynamic activity quantities in aqueous sodium and potassium chloride solutions at $25^{\circ} \mathrm{C}$. J. Chem. Eng., 2009. 54(2): p. 208-219.

21. Achilli, A., T.Y. Cath, and A.E. Childress, Power generation with pressure retarded osmosis: An experimental and theoretical investigation. Journal of Membrane Science, 2009. 343(1-2): p. 42-52.

22. B. Mi, M.E., Chemical and physical aspects of organic fouling of forward osmosis membranes. J. Membr. Sci., 2008. 320: p. 292-302.

23. Petersen, R.J., Composite reverse osmosis and nanofiltrationmembranes. J. Membr. Sci., 1993. 83(1): p. 81-150.

24. D. Xiao, C.Y.T., J. Zhang, W.C.L. Lay, R. Wang, A.G. Fane, Modeling salt accumulation in osmotic membrane bioreactors: implications for FO membrane selection and system operation,. J. Membr. Sci., 2011. 366: p. 314-324.

25. S. Zou, Y.G., D. Xiao, C.Y. Tang, The role of physical and chemical parameters on forward osmosis membrane fouling during algae separatio. J. Membr. Sci., 2011. 366: p. 356-362.

26. X. Jin, C.Y.T., Y. Gu, Q. She, S. Qi, , Boric acid permeation in forward osmosis membrane processes: Modeling, experiments, and implications. Environ. Sci. Technol., 2011. 45(6): p. 2323-2330.

27. G. Han, T.S.C., M. Toriida, S. Tamai, Thin-film composite forward osmosis membranes with novel hydrophilic supports for desalination. J. Membr. Sci., 2012. 423-424: p. 543-555.

28. W.A. Phillip, J.S.Y., M. Elimelech, Reverse draw solute permeation in forward osmosis: modeling and experiments. Environmental Science \& Technology, 2010. 44: p. 5170-5176. 